\title{
Indications and Overuse of Computed Tomography in Minor Head Trauma
}

\author{
Sanaz Zargar Balaye Jame ${ }^{1}$; Reza Majdzadeh ${ }^{2,3}$; Ali Akbari Sari ${ }^{1,3, *}$; Arash Rashidian ${ }^{1,3}$; \\ Mohammad Arab ${ }^{1}$; Hojjat Rahmani ${ }^{4}$ \\ ${ }_{1}^{1}$ Department of Health Management and Economics, School of Public Health, Tehran University of Medical Sciences, Tehran, IR Iran \\ ${ }^{2}$ Department of Epidemiology and Biostatistics, School of Public Health, Tehran University of Medical Sciences, Tehran, IR Iran \\ 3 Knowledge Utilization Research Center, Tehran University of Medical Sciences, Tehran, IR Iran \\ ${ }^{4}$ Department of Health Care Management, School of Applied Medical Sciences, Tehran University of Medical Sciences, Tehran, IR Iran \\ *Corresponding Author: Ali Akbari Sari, Department of Health Management and Economics, and Knowledge Utilization Research Center, School of Public Health, Tehran University \\ of Medical Sciences, Poorsina St, Tehran, IR Iran. Tel: +98-2188989129, Fax: +98-2188989129, E-mail: akbarisari@tums.ac.ir
}

Received: June 19, 2013; Revised: July 29, 2013; Accepted: August 19, 2013

Background: Computed Tomography (CT) is a useful diagnostic technology, particularly in accident and emergency departments. Objectives: To identify a comprehensive list of indications for application of CT in patients with minor head trauma (MHT) and to determine appropriateness of its use on the basis of this list.

Materials and Methods: A cross-sectional study was conducted in three Imaging centers in Tehran. A panel of experts developed a list of CT indications for MHT by reviewing documents. A pre-structured checklist was designed and incorporated into a structured form. Four hundred consecutive patients referring to three imaging centers for performing CT due to MHT completed the questionnaire.

Results: Of 400 patients who underwent CT after MHT, 187 (46.8\%) patients had Glasgow coma scale (GCS) score of 13 or 14 at two hours post-trauma and 37 (19.8\%) of these patients did not have any indication of imaging. In addition, 213 (53.2\%) patients had GCS score of 15 out of which 110 (51.6\%) patients did not have any indication of imaging. Patients with a GCS score of 15 had a noticeably lower proportion of abnormal CT results in comparison to patients with a GCS score of 13 or 14, (odds ratio, 19.07; 95\% confidence interval, 6.74-54.00; and $\mathrm{P}<0.001$ ). There was a statistically significant association between abnormal CT results and the presence of indications including vomiting, dangerous mechanism of injury, visible signs of trauma above the clavicles, signs of skull base fracture, and suspected skull fracture $(\mathrm{P}<0.001)$.

Conclusions: On average, about $37 \%$ of the patients with MHT referring to the emergency departments had no indication of CT and approximately $86.5 \%$ of CT results were normal. Improving this situation can result in a significant saving in health care costs.

Keywords: Tomography, X-Ray Computed; Craniocerebral Trauma; Indication; Abnormal

\section{Background}

Computed Tomography (CT) is an important diagnostic tool in many emergent conditions; however, it might be overused in many health care systems. This might lead to a significant drain on health care resources as well as increased risk of radiation exposure $(1,2)$. The growing number of appearing health technologies helps to fulfill both patients' and physicians' demands (3). Studying the utilization patterns of diagnostic imaging technologies is important for health care management, especially in developing or underdeveloped countries (4). Medical imaging costs have had an increasing trend all over the world, which might be a result of their overuse (5). There are many methods and criteria for evaluating the appropriateness of health care services (6). Decision principles can not only decline the costs and the number of performed imaging, but also decrease the emergency and radiology wards overcrowding (7).

Nearly, half of the all CT scans performed in the emergency departments are head scans $(8,9)$. A recent study has shown that $10 \%$ reduction in the number of CT scans in patients with minor head trauma (MHT) could lead to an annual saving of more than 20 million dollars (10). It seems that in Iran, a significant proportion of CT scans is performed without any indication. This issue, however, has not been well studied in Iran.

\section{Objectives}

The objectives of this study were to identify a comprehensive list of indications for utilization of CT scan in patients with MHT and to determine the level of appropriate use of this tool in MHT patients based on this list in Iran. tions. With improving proper access to computed tomography, it also helps to manage the flow of patients who need this diagnostic technology.

Copyright (C) 2014, Iranian Red Crescent Medical Journal; Published by Kowsar Corp. This is an open-access article distributed under the terms of the Creative Commons Attribution License, which permits unrestricted use, distribution, and reproduction in any medium, provided the original work is properly cited. 


\section{Materials and Methods}

\subsection{Identifying the List of Indications of the Com- puted Tomography in Minor Head Trauma}

Medline was searched to identify the reports concerning appropriateness criteria, standards, and indications of CT in patients with MHT. Nine relevant documents were identified of which one report provided a comprehensive list of the indications (11). We also added related items that were identified in other reports to complete the list of indications (12-18).

An applied method for head injury classification is dividing head injuries into minor or major groups based on patient's Glasgow coma scale (GCS) score. Trauma management starts with determination of the patients' GCS in the initial assessment. This scale is apparently correlated with severity of the damage happening inside the skull; besides, it can be measured with sufficient reliability by the health care providers. Therefore, GCS is a widely accepted measure of severity of neurological trauma. Major head injury includes patients with GCS score of 3 to 12 . Minor head injury includes patients with GCS score of 13 to 15 (7).

The list of indications was translated into Farsi and was checked by two physicians. Six specialist residents from the three major specialties, namely emergency medicine, neurosurgery, and neurology who are involved in the ordering of CT for MHT, were assigned to check the structure and content validity of the questionnaire. The preliminary checklist was sent to these residents and based on their comments, we modified the questionnaire. The final list of indications was identified based on the general consensus made on the panel of these six residents. The panel approved nine indications out of the ten indications that were identified by the literature review. Head CT scan in patients with MHT (GCS of 13 to 15 ) was necessary only when one or more clinical risk factors were observed. Abnormal CT findings included the results that required neurosurgical care (observational or interventional).

\subsection{Setting, Sampling, and Patient Recruitment for Field Study}

The following formula was used for sample size calculation: $\mathrm{n}=\mathrm{Z}^{2} \mathrm{pq} / \mathrm{d}$. The field study was performed in three imaging centers in two large public hospitals and a medium military hospital in Tehran. Then 150 and 100 consecutive patients from each large hospital and the medium hospital, respectively, were selected. Overall, 400 individuals from both genders were recruited from September to December 2012.

The prestructured checklist was used to obtain the information from selected patients through face to face interviews by trained interviewers (emergency department nurses) and patients' medical records. The inclusion cri- teria were GCS score of $13-15$, age $\geq 3$ years, and a MHT during the past 12 hours. Collected data were analyzed using SPSS v. 19 software for Windows (SPSS Inc., Chicago, Illinois). Chi-square and Fisher's exact tests were used to evaluate statistical significance. We quantified the strength of associations using the odds ratio.

\subsection{Ethical Concerns}

The Institutional Review Board of Tehran University of Medical Sciences approved this study (number: 18741, January 16, 2012). Hospitals administrators agreed with implementing the study at the emergency departments. Verbal permission was taken from patients and their relatives after explaining the importance of the study. Participation in the study was voluntarily and based on the informed consent obtained before completing the questionnaire. We did not perform any intervention in the study and did not make any change in the process of patient diagnosis and treatment.

\section{Results}

Of 400 patients, 228 (57\%) respondents were males. The patients' average age was $36.9 \pm 19.6$ years. Overall, 262 (65.5\%) patients had insurance coverage. Amongst the respondents, $23 \%, 42 \%$, and $88.8 \%$ were housewives, had diploma education level, and lived in urban areas, respectively.

\subsection{Indications of Computed Tomography in Patients With Minor Head Trauma}

Among the study participants, 147 (36.8\%) patients had no indication and $253(63.2 \%)$ patients had at least one indication of CT. Approximately, $86.5 \%$ of CT findings were normal. From 253 patients that had indications of CT, 180 (45\%) and 88 (22\%) patients underwent CT due to dangerous mechanism of injury and signs of skull base fracture, respectively (Table 1 ).

The GCS score of 13 to14 at two hours post-trauma was reported in 187 (46.8\%) patients among which 37 (19.8\%) patients did not have any other risk factors. GCS score of 15 was reported in 213 (53.2\%) patients among which 110 (51.6\%) patients did not have any other risk factors. CT reports according to GCS score are shown in Table 2.

In terms of abnormal CT results, there was a major difference between patients with the GCS score of 13 to 14 and those with the GCS score of 15 (odds ratio, 19.07; 95\% confidence interval, 6.74-54.00; and $\mathrm{P}<0.001$ ).

The correlation between the indications of CT and abnormal findings are shown in Table 3. There was a statistically significant association between abnormal findings in CT and the indications of CT including vomiting, dangerous mechanism of injury, visible signs of trauma above the clavicles, signs of skull base fracture, and suspected skull fracture $(P<0.001)$. The risk of abnormal CT findings in patients with signs of 
Table 1. Patients With Indications of Computed Tomography and Abnormal Computed Tomography Findings at the Same Time $(n=400)^{\text {a }}$

\begin{tabular}{|c|c|c|}
\hline Reason for $\mathrm{CT}^{\mathrm{b}}$ & Indications & $\begin{array}{l}\text { Abnormal CI } \\
\text { Reports }^{c}\end{array}$ \\
\hline $\begin{array}{l}\text { Dangerous mechanism of } \\
\text { injury }\end{array}$ & $180(45)$ & $45(11.3)$ \\
\hline $\begin{array}{l}\text { Pedestrian or cyclist crash by } \\
\text { a motor vehicle }\end{array}$ & $92(23)$ & $22(5.5)$ \\
\hline $\begin{array}{l}\text { Occupant ejected from a mo- } \\
\text { tor vehicle }\end{array}$ & $9(2.2)$ & $8(2)$ \\
\hline $\begin{array}{l}\text { Fall from a height }>1 \mathrm{~m} \text { or } \\
\text { five stairs }\end{array}$ & $79(19.8)$ & $15(3.8)$ \\
\hline Signs of skull base fracture & $88(22)$ & $40(10)$ \\
\hline Hemotympanum & $2(0.5)$ & 0 \\
\hline Raccoon eyes & $62(15.5)$ & $25(6.3)$ \\
\hline CSF Otorrhea/Rhinorrhea & $10(2.5)$ & $5(1.3)$ \\
\hline Battle sign & $5(1.3)$ & $2(0.5)$ \\
\hline Raccoon eyes \& Battle sign & $5(1.3)$ & $4(1)$ \\
\hline $\begin{array}{l}\text { CSF Otorrhea/Rhinorrhea \& } \\
\text { Battle sign }\end{array}$ & $2(0.5)$ & $2(0.5)$ \\
\hline All Signs & $2(0.5)$ & $2(0.5)$ \\
\hline $\begin{array}{l}\text { Suspected skull fracture } \\
\text { (open or depressed) }\end{array}$ & $70(17.5)$ & $34(8.5)$ \\
\hline$>1$ episode of vomiting & $40(10)$ & $13(3.3)$ \\
\hline Age $\geq 65$ years & $29(7.2)$ & $7(1.8)$ \\
\hline $\begin{array}{l}\text { Visible signs of trauma } \\
\text { above the clavicle }\end{array}$ & $12(3)$ & $8(2)$ \\
\hline Seizure & $9(2.2)$ & $1(0.3)$ \\
\hline $\begin{array}{l}\text { Amnesia for events }>30 \mathrm{~min} \\
\text { before incident }\end{array}$ & $7(1.8)$ & 0 \\
\hline Coagulopathy & 0 & 0 \\
\hline $\begin{array}{l}\text { Patient with } 2 \text { indications } \\
\text { simultaneously }\end{array}$ & $86(21.5)$ & $23(5.7)$ \\
\hline $\begin{array}{l}\text { Patient with } 3 \text { indications } \\
\text { simultaneously }\end{array}$ & $31(7.8)$ & $20(5)$ \\
\hline $\begin{array}{l}\text { Patient with } 4 \text { indications } \\
\text { simultaneously }\end{array}$ & $10(2.5)$ & $9(2.2)$ \\
\hline $\begin{array}{l}\text { Patient with } 5 \text { indications } \\
\text { simultaneously }\end{array}$ & $1(0.3)$ & $1(0.3)$ \\
\hline $\begin{array}{l}\text { Patients with at least one } \\
\text { indication }\end{array}$ & $253(63.2)$ & $54(13.5)$ \\
\hline No indications & $147(36.8)$ & 0 \\
\hline Total patients & $400(100)$ & $54(13.5)$ \\
\hline
\end{tabular}

${ }^{a}$ Data are presented as No. (\%).

b Abbreviations: CT, computed tomography; CSF, cerebrospinal fluid 'The declared percentages are from the total sample.

skull base fracture, visible signs of trauma above the clavicle, and suspected skull fracture were respectively $17.7,14.8$, and 14.6 times more than in patients without these findings.
Table 2. Computed Tomography Findings According to Glasgow Coma Scale Score $(n=400)$

\begin{tabular}{|c|c|c|c|c|c|}
\hline GCS $^{\text {a }}$ score & GCS $=13$ & & GCS $=1$ & & Total \\
\hline CT report & No. $(\%)^{b}$ & $\%^{c}$ & No. (\%) & $\%$ & \\
\hline Normal & $137(34.3)$ & 73.3 & $209(52.2)$ & 98.1 & $346(86.5)$ \\
\hline Abnormal & $50(12.5)$ & 26.7 & $4(1)$ & 1.9 & $54(13.5)$ \\
\hline Total & $187(46.8)$ & 100 & $213(53.2)$ & 100 & $400(100)$ \\
\hline
\end{tabular}

Table 3. Association of Indications With Abnormal Computed Tomography Findings $(n=400)^{\text {a }}$

\begin{tabular}{|c|c|c|c|}
\hline Indications & Odds Ratio & $\mathrm{CI}(95 \%)$ & Pvalue $^{b}$ \\
\hline $\begin{array}{l}\text { Dangerous mechanism } \\
\text { of injury }\end{array}$ & 7.8 & $3.70-16.50$ & $<0.001$ \\
\hline $\begin{array}{l}\text { Signs of skull base } \\
\text { fracture }\end{array}$ & 17.7 & $8.98-35.04$ & $<0.001$ \\
\hline $\begin{array}{l}\text { Suspected skull fracture } \\
\text { (open or depressed) }\end{array}$ & 14.6 & $7.63-28.10$ & $<0.001$ \\
\hline$>1$ episode of vomiting & 3.7 & $1.80-7.83$ & $<0.001$ \\
\hline Age $\geq 65$ years & 2.1 & $0.85-5.14$ & 0.1 \\
\hline $\begin{array}{l}\text { Visible signs of trauma } \\
\text { above the clavicle }\end{array}$ & 14.8 & $4.31-51.34$ & $<0.001$ \\
\hline Seizure & 0.8 & $0.10-6.50$ & 0.83 \\
\hline $\begin{array}{l}\text { Amnesia for events }>30 \\
\text { min before incident }\end{array}$ & - & - & 0.292 \\
\hline
\end{tabular}

The most common causes of head injuries were car accidents, falling from the height, street fights, falling to the ground, and trauma on face, consecutively, that were seen in 179 (44.7\%), 97 (24.3\%), 62 (15.5\%), 49 (12.2\%), and 13 (3.3\%) patients, respectively. The majority of CTs were requested by emergency physicians, followed by neurosurgeons and ENT specialists who ordered 369 (92.3\%), 14 (3.5\%), and 8 (2\%) CTs, respectively (Table 4). A comparison between emergency physicians and other specialists who ordered CT showed that emergency physicians ordered CT according to the indications list about 2.5 times more than other specialists $(\mathrm{P}=0.01)$.

Table 4 shows the association between the specialty of physicians who ordered CT scans and existence of CT the indications. According to the indications list, the risk of inappropriate ordering of CT by ear, nose, and throat (ENT) specialists was about five times more than by emergency physicians. Sixty-one (15.2\%) patients had at least one history of previous CT for MHT during the past 12 hours (Table 5). Among them, 26 (42.6\%) patients did not have any indications of CT according to the indications list. In this study, 194 (48.5\%) and 206 (51.5\%) patients had and had not skull X-Ray for MHT prior to CT, respectively. 
Table 4. The Association of Indication of Computed Tomography With Specialist Physicians Who Ordered the Imaging $(\mathrm{n}=400)^{\mathrm{a}}$

\begin{tabular}{|c|c|c|c|c|c|}
\hline \multirow[t]{2}{*}{ Specialties } & \multicolumn{2}{|c|}{ Indication } & \multirow{2}{*}{$\begin{array}{l}\text { Odds } \\
\text { Ratio }\end{array}$} & \multirow[t]{2}{*}{$\mathrm{CI}(95 \%)$} & \multirow[t]{2}{*}{ Pvalue $^{b}$} \\
\hline & Yes & No & & & \\
\hline $\begin{array}{l}\text { Emergency ph- } \\
\text { ysician }\end{array}$ & 240 & 129 & 1 & - & - \\
\hline Neurosurgeon & 8 & 6 & 1.30 & $0.44-3.83$ & 0.63 \\
\hline ENT Specialist & 2 & 6 & 5.34 & $1.06-26.81$ & 0.06 \\
\hline General surgeon $\mathrm{C}$ & 3 & 0 & - & - & 0.30 \\
\hline Neurologist ${ }^{c}$ & 0 & 2 & - & - & 0.13 \\
\hline Orthopedist ${ }^{C}$ & 0 & 2 & - & - & 0.13 \\
\hline Pediatrician ${ }^{C}$ & 0 & 2 & - & - & 0.13 \\
\hline Total & 253 & 147 & & & \\
\hline
\end{tabular}

a Abbreviation: $\mathrm{CI}$, confidence interval.

${ }^{\mathrm{b}}$ A P value less than 0.05 is statistically significant.

${ }^{\mathrm{c}}$ Because the cell count in the table was zero, the calculation of odds ratio was not possible.

Table 5. History of Previous Computed Tomography During the Past Twelve Hours $(n=400)$

\begin{tabular}{lcccccc}
\hline History of & \multicolumn{3}{c}{ Indication } & \multicolumn{3}{c}{ CT Result } \\
\cline { 2 - 7 } Previous CT & Yes & No & Total & Normal & Abnormal & Total \\
\hline At least one & 35 & 26 & 61 & 47 & 14 & 61 \\
No history & 218 & 121 & 339 & 299 & 40 & 339 \\
Total & 253 & 147 & 400 & 346 & 54 & 400 \\
\hline
\end{tabular}

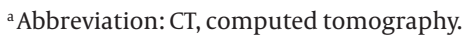

\section{Discussion}

The list of indications based on the world's most famous guidelines is nearly comprehensive and we tried to design it according to facilities existing in our country and recommendations of the specialists who ordered CT in public and private hospitals.

GCS scoring system is the standard method for evaluating the patient situation worldwide (19). It seems that this system is also widely used in Iran. In our study, approximately $37 \%$ of the patients did not have any indication of CT and no abnormal CT finding was reported in this group. Moreover, $13.5 \%$ of all patients undergone CT scan had abnormal CT reports. All patients with abnormal CT results had at least one of the indications.

Melnick et al. found that in the emergency department, about $10 \%$ to $35 \%$ of CT scans for patients with MHT were not indicated by evidence-based guidelines. They also concluded that effective implementation of the guiding principles could probably decrease ordering CT scans in MHT up to $35 \%$ and would cause a prominent decrease in health care costs. Their results were approximately similar to ours (9).

A study by the World Health Organization (WHO) showed that, the rate of abnormal CT results was approxi- mately 5\% in patients with GCS score of 15 and this rate may increase to $30 \%$ in patients with GCS score of 13 (20). Our findings demonstrated the percentages that were lower than the mentioned range that could be due to using different guidelines.

A recent study indicated that $13 \%$ of the patients with MHT (GCS score $\geq 13$ ) had abnormal findings in CT. In addition, patients younger than 65 years old with no obvious head injury, raccoon eyes, vomiting, and amnesia had normal CT results (21). Thus, the first part of their results approves our findings but with respect to the second part of their results, we attained different findings. A study by Iverson et al. demonstrated that the rate of abnormal CT results in MHT was about $16 \%$ and there was a statistically major link between the presence of intracranial abnormalities and lower GCS scores (22). In addition, a study by Ibanez et al. showed that patients with MHT had abnormal CT scans in $7.5 \%$ of the cases (23). Therefore, our findings demonstrated a rate between the results of the two studies and showed a statistically significant association between abnormal CT results and lower GCS scores.

Haydel et al. conducted a study in which about $6.5 \%$ of patients with MHT had an abnormal CT results. They also concluded that in MHT, CT could be performed only for patients with specific indications, which were similar to the mentioned risk factors in our study (10). In Turkey, Turedi et al. pointed out that in terms of abnormal CT findings, the difference between patients with GCS score of 13 to 14 and patients with GCS score of 15 was statistically significant $(\mathrm{P}<0.0005)$. Moreover, the presence of two indications including vomiting and suspected skull fracture was significantly correlated with abnormal CT findings (respectively: OR, 4.61; 95\% CI, 2.20-9.64; $\mathrm{P}=0.0001$; and $\mathrm{OR}, 3.46$; 95\% CI, 1.52-7.91; $\mathrm{P}=0.0032)(24)$. Our findings were in line with the findings of the aforementioned study.

Two famous guidelines for ordering head CT after MHT (the Canadian CT Head Rules and the New Orleans Criteria) were compared in a study by Stiell et al. They demonstrated that the Canadian rules were more detailed; hence, using these rules caused a great decrease (25\% to $50 \%$ ) in the number of scans $(11,18)$. According to this study, the importance of attention to developing and implementing national guidelines regarding clinical status, resources, and the existing facilities access level is completely distinguished. Applying Clinical Practice Guidelines (CPGs) in the decision making process can help to improve the appropriate use of these diagnostic technologies. To our knowledge, there was no national guideline for referring patients with MHT to perform a CT scan up to the current study. A study in Iran on obstacles of CPGs development and implementation illustrated that the lack of an evidence-based health care system and a political macro support are the key barriers to produce and implement the CPGs (25). This study showed that a large number (37\%) of patients with MHT that underwent CT scan in the emergency depart- 
ments had no indication of CT; in addition, the majority (86.5\%) of CT results were normal. The results of this study can be useful for the health specialists and policy makers in order to develop national guidelines toward appropriate use of health technologies and consider cost-effectiveness of these technologies. The use of best practice guidelines to manage the flow of patients who need a CT would help to improve proper access to this diagnostic tool and would decrease health care costs. Moreover, physicians' decision making process would be easier when they order imaging on the basis of a national guideline.

Some limitations restricted the generalizability of the results of this study. The majority of patients were from urban area with insurance coverage and the results were based on the hospitals of Tehran city; therefore, other studies must be managed in other parts of the country to increase the generalizability of the results of this study. Moreover, it is possible that we had excluded some indications for which we could not make the consensus on the expert panel and this might have led to a slight overestimation of the inappropriate use of CT. Thus, results must be interpreted with cautions.

\section{Acknowledgements}

The authors would like to thank the Deputy of Research at Tehran University of Medical Sciences for their help and financial support. We also thank members of the expert panel (specialist residents at Tehran University of Medical Sciences).

\section{Authors' Contribution}

Sanaz Zargar Balaye Jame, Ali Akbari Sari, Reza Majdzadeh, Arash Rashidian, Mohammad Arab, and Hojjat Rahmani conceived the study and developed the methods. Sanaz Zargar Balaye Jame collected the data. Sanaz Zargar Balaye Jame, Ali Akbari Sari, and Reza Majdzadeh analyzed the data and wrote the primary draft of the manuscript. All of the authors contributed to the revision of the manuscript, read, and approved the final version.

\section{Financial Disclosure}

The authors declared no financial interests related to the material in the manuscript. In addition, there was no conflict of interest.

\section{Funding/Support}

This study as a research project (number 18741 dated January 16, 2012) was financially supported by Tehran University of Medical Sciences (TUMS). In addition, it was part of a PhD thesis by Sanaz Zargar Balaye Jame and was supported by School of Public Health in Tehran University of Medical Sciences.

\section{References}

1. Kandogan T, Dalgic A, Mollamehmetoglu H, Esen O. Combined aplasia of sphenoid, frontal, and maxillary sinuses with hypoplasia of the ethmoid sinus. Iran Red Crescent Med J. 2013;15(1):13-4.

2. Frush DP, Donnelly LF, Rosen NS. Computed tomography and radiation risks: what pediatric health care providers should know. Pediatrics. 2003;112(4):951-7.

3. Palesh M, Tishelman C, Fredrikson S, Jamshidi H, Tomson G, Emami A. "We noticed that suddenly the country has become full of MRI". Policy makers' views on diffusion and use of health technologies in Iran. Health Res Policy Syst. 2010;8:9.

4. Palesh M, Fredrikson S, Jamshidi H, Tomson G, Petzold M. How is magnetic resonance imaging used in Iran? Int J Technol Assess Health Care. 2008;24(4):452-8.

5. Keshtkaran A, Bagheri MH, Ostovar R, Salari H, Farokhi MR, Esfandiari A, et al. Developing Criteria for Lumbar Spine Magnetic Resonance Imaging (MRI) Using RAND Appropriateness Method (RAM). Iran J Radiol. 2012;9(3):130-8.

6. Ostovar R, Rashidian A, Pourreza A, Rashidi BH, Hantooshzadeh $S$, Ardebili HE, et al. Developing criteria for cesarean section using the RAND appropriateness method. BMC Pregnancy Childbirth. 2010;10:52.

7. Shoar S, Saadat S. CT Scanning in Minor Head Injury. In: Subburaj $\mathrm{K}$, editor. CT Scanning - Techniques and Applications: InTechOpen; 2011. p.161-77.

8. Lee J, Kirschner J, Pawa S, Wiener DE, Newman DH, Shah K. Computed tomography use in the adult emergency department of an academic urban hospital from 2001 to 2007. Ann Emerg Med. 2010;56(6):591-6.

9. Melnick ER, Szlezak CM, Bentley SK, Dziura JD, Kotlyar S, Post LA CT overuse for mild traumatic brain injury. Jt Comm J Qual Patient Saf. 2012;38(11):483-9.

10. Haydel MJ, Preston CA, Mills TJ, Luber S, Blaudeau E, DeBlieux PM. Indications for computed tomography in patients with minor head injury. NEngl J Med. 2000;343(2):100-5.

11. Stiell IG, Wells GA, Vandemheen K, Clement C, Lesiuk H, Laupacis A, et al. The Canadian CT Head Rule for patients with minor head injury. Lancet. 2001;357(9266):1391-6.

12. Edlow JA, Panagos PD, Godwin SA, Thomas TL, Decker WW, American College of Emergency P. Clinical policy: critical issues in the evaluation and management of adult patients presenting to the emergency department with acute headache. Ann Emerg Med. 2008;52(4):407-36.

13. Smits M, Dippel DW, de Haan GG, Dekker HM, Vos PE, Kool DR, et al. Minor head injury: guidelines for the use of CT--a multicenter validation study. Radiology. 2007;245(3):831-8.

14. Ingebrigtsen $\mathrm{T}$, Romner B, Kock-Jensen C. Scandinavian guidelines for initial management of minimal, mild, and moderate head injuries. The Scandinavian Neurotrauma Committee. JTrauma. 2000;48(4):760-6.

15. Yates D, Breen K, Brennan P. Head injury: triage, assessment, investigation and early management of head injury in infants, children and adults. United Kingdom National Institute for Clinical Excellence Guideline Development Group; 2007.

16. Vos PE, Battistin L, Birbamer G, Gerstenbrand F, Potapov A, Prevec T, et al. EFNS guideline on mild traumatic brain injury: report of an EFNS task force. EurJ Neurol. 2002;9(3):207-19.

17. Servadei F, Teasdale G, Merry G, Neurotraumatology Committee of the World Federation of Neurosurgical S. Defining acute mild head injury in adults: a proposal based on prognostic factors, diagnosis, and management. J Neurotrauma. 2001;18(7):657-64.

18. Stiell IG, Clement CM, Rowe BH, Schull MJ, Brison R, Cass D, et al. Comparison of the Canadian CT Head Rule and the New Orleans Criteria in patients with minor head injury. JAMA. 2005;294(12):1511-8.

19. Teasdale G, Jennett B. Assessment of coma and impaired consciousness. A practical scale. Lancet. 1974;2(7872):81-4

20. Borg J, Holm L, Cassidy JD, Peloso PM, Carroll LJ, von Holst H, et al. Diagnostic procedures in mild traumatic brain injury: results of the WHO Collaborating Centre Task Force on Mild Traumatic Brain Injury. J Rehabil Med. 2004;43(Suppl):61-75. 


\section{Zargar Balaye Jame S et al.}

21. Saadat S, Ghodsi SM, Naieni KH, Firouznia K, Hosseini M, Kadkhodaie HR, et al. Prediction of intracranial computed tomography findings in patients with minor head injury by using logistic regression. J Neurosurg. 2009;111(4):688-94.

22. Iverson GL, Lovell MR, Smith S, Franzen MD. Prevalence of abnormal CT-scans following mild head injury. Brain Inj. 2000;14(12):1057-61.

23. Ibanez J, Arikan F, Pedraza S, Sanchez E, Poca MA, Rodriguez D, et al. Reliability of clinical guidelines in the detection of patients at risk following mild head injury: results of a prospective study. J Neurosurg. 2004;100(5):825-34.

24. Turedi S, Hasanbasoglu A, Gunduz A, Yandi M. Clinical decision instruments for CT scan in minor head trauma. J Emerg Med. 2008;34(3):253-9.

25. Baradaran-Seyed Z, Nedjat S, Yazdizadeh B, Nedjat S, Majdzadeh R. Barriers of clinical practice guidelines development and implementation in developing countries: a case study in iran. Int J Prev Med. 2013;4(3):340-8. 